\title{
Impact of the COVID-19 Lockdown on Indian Patients Undergoing Orthodontic Treatment: A Questionnaire Based Study
}

\author{
Oishi Chatterjee ${ }^{1}$, Kanchan Sharma ${ }^{2}$, Subhash Kumar ${ }^{3}$, Archana Kumari ${ }^{4}$, \\ Komal Neha ${ }^{5}$, Mrinal Kumar Nandi ${ }^{6}$ \\ ${ }^{1}$ Final Year Postgraduate Trainee, Department of Orthodontics and Dentofacial Orthopedics, \\ Awadh Dental College and Hospital, Jharkhand, India \\ 2,3,5,6 Assistant Professor, Department of Orthodontics and Dentofacial Orthopedics, \\ Awadh Dental College and Hospital, Jharkhand, India \\ ${ }^{4}$ Reader, Department of Orthodontics and Dentofacial Orthopedics, Awadh Dental College and Hospital \\ Corresponding Author: Oishi Chaaterjee
}

DOI: https://doi.org/10.52403/ijhsr.20220306

\begin{abstract}
Introduction: The restrictions on patients concerning visiting their orthodontists as implemented by the lockdown guidelines created tremendous impact on the treatment procedure. The present study was conducted to evaluate the impact of the COVID-19 lockdown on the Indian patients undergoing orthodontic treatment.

Materials and Methods: A questionnaire was prepared that consisted of 12 questions. The questionnaires were distributed to the patients undergoing orthodontic treatment through email and WhatsApp messages. Online informed consents were obtained from them and they were requested to respond within two weeks.

Results: The female patients were found to be more apprehensive and anxious about the prolonged treatment duration, discomfort during the lockdown period, financial issues and treatment outcomes.

Conclusion: The lockdown made the orthodontic patients worried about the future of their treatment. A healthy discussion regarding all the possible issues in this critical time between the doctors and the patients is desirable.
\end{abstract}

Keywords: Orthodontic treatment, lockdown, anxiety, questionnaire

\section{INTRODUCTION}

It was January 30, 2020, when the World Health Organization (WHO) declared the novel coronavirus disease-2019 (COVID-19) pandemic as a public health emergency. And from March 25, 2020 onwards, Government of India declared a nationwide lockdown. The first phase of the lockdown began on March 25, 2020 and lasted for 21 days, followed by the second phase starting on April 15, 2020 and ending on May 3, 2020. The third and fourth phases began on May 4, 2020 and May 18, 2020 respectively and lasted for 2 weeks. ${ }^{1-3}$
As the disease is a transmissible one (through the respiratory tract via droplets, respiratory secretions like cough, sneeze and direct contact), it has significant impact on healthcare profession including the dental healthcare. The Indian Dental Association (IDA), the Dental Council of India (DCI) and the Ministry of Health and Family Welfare (MoHFW) issued several guidelines for dental professionals allowing only emergency dental procedures. Modifications of dental clinics, hospitals and academic institutions were also mentioned as per WHO and CDC 
guidelines. A huge gap between the demand and supply operations with acute shortage of routine dental treatments were a nationwide scenario which was imposed by the lockdown. ${ }^{4-7}$

Orthodontic treatments are not usually considered as emergency. Still, regular check-ups or monthly visits are inseparable part of it. The restrictions on patients concerning visiting their orthodontists as implemented by the lockdown guidelines created tremendous impact on the treatment procedure. In this crucial time, it became important to assess the perspectives of the patients; whether they understand the significance of regular follow-ups, whether there is any anxiety in their mind regarding the treatment modalities or whether they realize the detrimental effect of prolonged orthodontic treatment during. With this background, the present study was conducted to evaluate the impact of the COVID-19 lockdown on the Indian patients undergoing orthodontic treatment.

\section{MATERIALS AND METHODS}

\section{A. Clearance from the Ethical Committee:}

The ethical clearance certificate was obtained from the Institutional Ethical Committee of Awadh Dental College and Hospital, Jamshedpur, Jharkhand.

\section{B. Study design and sample selection:}

The cross-sectional study was conducted in the Department of Orthodontics and Dentofacial Orthopaedics, Awadh Dental College and Hospital, Jamshedpur, Jharkhand. The study population was the patients from Jharkhand who were on orthodontic treatment before the lockdown but the treatment was suspended due the onset of COVID-19 lockdown. The sample size was estimated as 500. A questionnaire was prepared that consisted of 12 questions. It was mandatory to answer all the questions. The validity and reliability of the questionnaire were evaluated prior to the study. The questionnaires were distributed to the patients through email and WhatsApp messages. Online informed consents were obtained from them and they were requested to respond within two weeks.

\section{Statistical Analysis:}

The data from the responses were tabulated in Microsoft Excel and analysed with SPSS V.24 (Statistical Package for Social Sciences, IBM Corp., Armonk, NY). The descriptive analysis included the expression of participants' responses to the study questionnaire using frequency and proportions. Chi square test was used for the comparison between the responses. The $\mathrm{p}$ value $\leq 0.05$ was considered as statistically significant.

\section{RESULT}

Although the questionnaire was sent to 500 patients, only 400 responded. Demographic characteristics are shown in the Table 1 . Among of the patients $60 \%$ was female and $40 \%$ was male. Their ages were divided into 3 groups: <20 years, 20-25 years and $>25$ years. Majority of the patients (78\%) fell in the age group of 20-25 years. Table 2 shows the attitude of the patients towards the necessity of the lockdown. $75 \%$ of the male patients and $83.3 \%$ of the female patients agreed that the lockdown was necessary. This signifies that even they are in the need for regular visit, they will be safe of they follow the lockdown guidelines.

Table 3 shows the worries the patients experienced regarding their treatment during the lockdown. $93.7 \%$ of the male patients and $96.6 \%$ of the female patients agreed that they were worried about the continuation of their orthodontic treatment. As there was uncertainty about the longevity of the lockdown, they became anxious whether they will be able to receive the remaining part of their treatment in proper time. But the good thing is that, most of the patients were in contact with their orthodontists $(93.7 \%$ of the male patients and $96.6 \%$ of the female patients) as shown in the Table 4. Female patients were found to be more careful about their oral hygiene 
Oishi Chatterjee et.al. Impact of the COVID-19 lockdown on Indian patients undergoing orthodontic treatment: a questionnaire based study.

and following their orthodontist's instructions. Table 5 shows that, $91.7 \%$ of the female patients are maintaining their oral hygiene properly in the lockdown in comparison to $70 \%$ of the male patients and Table 6 shows that, $95.8 \%$ of the female patients were following their orthodontist's instructions regarding their appliances in comparison to $71.9 \%$ of the male patients. And most of patients having problems with their appliances were also female as shown in Table 7 ( $81.3 \%$ female and $51.6 \%$ male).

But the male and female patients almost equally agreed that they were anxious about the duration of the treatment. Table 8 shows $99.1 \%$ of the female patients and $97.5 \%$ of the male patients were anxious. One possible reason is that, as the lockdown was suddenly implemented and there is no prediction about its duration, the patients became anxious about whether they have to keep wearing the appliances for an uncertainly longer period. Along with the duration, they are also worried about the future cost of the treatment. Table 9 shows that, $85 \%$ of the female patients and $66.3 \%$ of the male patients expressed their worries as the longer duration of the treatment might increase the cost of it.

But the patients are hopeful about the end of the lockdown and expressed that they need to visit their orthodontists as soon as possible as shown in Table 10 (96.7\% of the female patients and $92.5 \%$ of the male patients). And almost all the patients agreed that they will strictly follow your orthodontist's instructions after you will have a chance for regular visit as shown in Table 11 (98.8\% of the male patients and $98.7 \%$ of the female patients). This signifies that they realize the importance of regular visit for orthodontic treatment.

Table 12 and Table 13 assessed their perspective towards their own orthodontists' practice during the lockdown. $93.7 \%$ of the female patients and $79.4 \%$ of the male patients agreed that they think your orthodontist has also been affected by the impact of this lockdown but $96.3 \%$ of the female patients and $93.2 \%$ of the male patients think your orthodontist will recover from the impact soon.

Table 1. Demographic characteristics

\begin{tabular}{|l|l|l|l|}
\hline Characteristics & n & \% \\
\hline \multirow{3}{*}{ Gender } & Male & 160 & 40 \\
\cline { 2 - 4 } & Female & 240 & 60 \\
\hline \multirow{3}{*}{ Age groups } & $<20$ years & 52 & 13 \\
\cline { 2 - 4 } & 20-25 years & 312 & 78 \\
\cline { 2 - 4 } & $>25$ years & 36 & 9 \\
\hline
\end{tabular}

Table 2. Do you think that implication of this lockdown was necessary especially when many people like you are under prolonged therapy and need regular visit to doctors?

\begin{tabular}{|l|l|l|l|}
\hline Responses & Male & Female & P value \\
\hline Yes & $120(75 \%)$ & $200(83.3 \%)$ & $<0.05$ \\
No & $30(18.7 \%)$ & $35(14.6 \%)$ & (significant) \\
\cline { 1 - 3 } Not sure & $10(6.3 \%)$ & $5(2.1 \%)$ & \\
\hline
\end{tabular}

Table 3. Are you worried about the continuation of your orthodontic treatment after the lockdown started?

\begin{tabular}{|l|l|l|l|}
\hline Responses & Male & Female & P value \\
\hline Yes & $150(93.7 \%)$ & $232(96.6 \%)$ & $<0.05$ \\
No & $2(1.3 \%)$ & $3(1.3 \%)$ & \multirow{2}{*}{ (significant) } \\
\cline { 1 - 3 } Not sure & $8(5 \%)$ & $5(2.1 \%)$ & \\
\hline
\end{tabular}

Table 4. Are you in contact with your orthodontist?

\begin{tabular}{|l|l|l|l|}
\hline Responses & Male & Female & P value \\
\cline { 1 - 3 } Yes & $155(96.8 \%)$ & $237(98.7 \%)$ & $<0.05$ \\
No & $5(3.2 \%)$ & $3(1.3 \%)$ & (significant) \\
\hline
\end{tabular}

Table 5. Are you maintaining proper oral hygiene?

Table 5. Are you maintaining proper oral hygiene?
\begin{tabular}{|l|l|l|l|}
\hline Responses & Male & Female & P value \\
\hline Yes & $112(70 \%)$ & $220(91.7 \%)$ & $<0.05$ \\
No & $3(1.9 \%)$ & $8(3.3 \%)$ & (significant) \\
\cline { 1 - 3 } Sometimes & $45(28.1 \%)$ & $12(5 \%)$ & \\
\hline
\end{tabular}

Table 6. Are you following your orthodontist's instructions regarding your appliance?

\begin{tabular}{|l|l|l|l|}
\hline Responses & Male & Female & P value \\
\hline Yes & $115(71.9 \%)$ & $230(95.8 \%)$ & $<0.05$ \\
No & $10(6.2 \%)$ & $4(1.7 \%)$ & \multirow{2}{*}{ (significant) } \\
\cline { 1 - 3 } Sometimes & $35(21.9 \%)$ & $6(2.5 \%)$ & \\
\hline
\end{tabular}

Table 7. Since the lockdown started, have you experienced any problems with your appliance?

\begin{tabular}{|l|l|l|l|}
\hline Responses & Male & Female & P value \\
\hline Yes & $82(51.6 \%)$ & $195(81.3 \%)$ & $>0.05$ \\
\cline { 1 - 3 } No & $78(48.7 \%)$ & $45(18.7 \%)$ & \\
\hline
\end{tabular}

Table 8. Are you anxious about the duration of the treatment?

\begin{tabular}{|l|l|l|l|}
\hline Responses & Male & Female & P value \\
\hline Yes & $156(97.5 \%)$ & $238(99.1 \%)$ & $<0.05$ \\
\cline { 1 - 3 } No & $4(2.5 \%)$ & $2(0.9 \%)$ & (significant) \\
\hline
\end{tabular}

Table 9. Are you worried about the future cost of the treatment?

\begin{tabular}{|l|l|l|l|}
\hline Responses & Male & Female & P value \\
\hline Yes & $106(66.3 \%)$ & $204(85 \%)$ & $<0.05$ \\
\cline { 1 - 3 } No & $10(6.2 \%)$ & $20(8.3 \%)$ & (significant) \\
\cline { 1 - 3 } Not sure & $44(27.5 \%)$ & $16(6.7 \%)$ & \\
\hline
\end{tabular}

Table 10. Following this lockdown, when are you planning to visit your orthodontist?

\begin{tabular}{|l|l|l|l|}
\hline Responses & Male & Female & P value \\
\hline As soon as possible & $\begin{array}{l}148 \\
(92.5 \%)\end{array}$ & $\begin{array}{l}232 \\
(96.7 \%)\end{array}$ & $\begin{array}{l}<0.05 \\
\text { (significant) }\end{array}$ \\
\cline { 1 - 3 } $\begin{array}{l}\text { When my orthodontist } \\
\text { will call me }\end{array}$ & $12(7.5 \%)$ & $8(3.3 \%)$ & \\
\hline
\end{tabular}


Oishi Chatterjee et.al. Impact of the COVID-19 lockdown on Indian patients undergoing orthodontic treatment: a questionnaire based study.

Table 11. Will you strictly follow your orthodontist's instructions after you will have a chance for regular visit?

\begin{tabular}{|l|l|l|l|}
\hline Responses & Male & Female & P value \\
\hline Yes & $158(98.8 \%)$ & $237(98.7 \%)$ & $<0.05$ \\
\cline { 1 - 3 } No & $0(0 \%)$ & $0(\%)$ & \multirow{2}{*}{ (significant) } \\
\cline { 1 - 3 } Not sure & $2(1.2 \%)$ & $3(1.3 \%)$ & \\
\hline
\end{tabular}

Table 12. Do you think your orthodontist has also been affected by the impact of this lockdown?

\begin{tabular}{|l|l|l|l|}
\hline Responses & Male & Female & \multirow{2}{*}{ P value } \\
\hline Yes & $127(79.4 \%)$ & $225(93.7 \%)$ & \multirow{2}{*}{$>0.05$} \\
\cline { 1 - 3 } Not sure & $20(12.5 \%)$ & $5(2.1 \%)$ & \\
\cline { 1 - 3 } & $13(8.1 \%)$ & $10(4.2 \%)$ & \\
\hline
\end{tabular}

Table 13. Do you think your orthodontist will recover from the impact soon?

\begin{tabular}{|l|l|l|l|}
\hline Responses & Male & Female & P value \\
\hline Yes & $149(93.2 \%)$ & $231(96.3 \%)$ & \multirow{2}{*}{$>0.05$} \\
\cline { 1 - 3 } No & $0(0 \%)$ & $0(0 \%)$ & \\
\cline { 1 - 3 } Not sure & $11(6.8 \%)$ & $9(3.7 \%)$ & \\
\cline { 1 - 3 }
\end{tabular}

\section{DISCUSSION}

The lockdown guidelines were constructed to make the people to maintain social distancing, avoid large gathering, limiting themselves to work from home and use personal protective equipment such as masks and gloves in order to prevent exposure to the infection. Among these situations dental professional are at a higher risk of contracting the infection as they directly deal with the oral fluids. In these circumstances, quarantine is the only available solution to prevent the spread of this infection which is attainable with responsibilities of patient care that is supposed to be dealt with minimum contact and continuous sanitization.

The present study was conducted to assess the impact of the COVID-19 lockdown on the Indian patients who are undergoing orthodontic treatment. The study revealed that the female patients are more prone to get worried and anxious regarding the continuation, duration and expenditure of their ongoing orthodontic treatment than male patients. As females are more concerned about their facial appearance in comparison to males, it is expected that they will be more tensed when their esthetics related treatment is hampered. Studies by Shenoi et al $(2020)^{8}$ and Sayers et al $(2007)^{9}$ showed similar results.

Communication on regular intervals is extremely important in a successful orthodontic treatment as it helps in the constant motivation to the patient to follow the instructions. ${ }^{10}$ The present study showed that not only majority of the patients were in touch with their doctors, they also followed their instructions and maintained proper oral hygiene though in these cases, females showed better performance than males.

Majority of the patients expressed their worries about increased duration as well as the treatment cost due to the lockdown as shown in the study of Shenoi et al $(2020)^{8}$. In such scenarios, the orthodontist can discuss the whole matter with the patients and even if the duration is prolonged or cost in increased a proper justification can maintain the healthy doctor-patient relationship. When the lockdown is absolutely barring the regular physical visits by the patients, advanced technologies like telecommunication, video conferencing etc. can be of use. And it will give the worried patients significant relief. ${ }^{11,12}$

\section{CONCLUSION}

The present study showed that the lockdown made the orthodontic patients worried about the future of their treatment. Along with the treatment strategies, the orthodontists should also take care of the psychological wellbeing of their patients. A healthy discussion regarding all the possible issues in this critical time between the doctors and the patients is desirable.

\section{Acknowledgement: None}

\section{Conflict of Interest: None}

\section{Source of Funding: None}

\section{Ethical Approval: Approved}

\section{REFERENCES}

1. Chen ZM, Fu JF, Shu Q, Chen YH, Hua CZ, $\mathrm{Li} \mathrm{FB}$, et al. Diagnosis and treatment recommendations for pediatric respiratory infection caused by the 2019 novel coronavirus. World J Pediatr. 2020;16:2406. 
Oishi Chatterjee et.al. Impact of the COVID-19 lockdown on Indian patients undergoing orthodontic treatment: a questionnaire based study.

2. Bhanushali P, Katge F, Deshpande S, Chimata VK, Shetty S, Pradhan D. COVID19: changing trends and its impact on future of dentistry. Int J Dent. 2020:8817424.

3. Paital B, Das K, Parida SK. Inter nation social lockdown versus medical care against COVID-19, a mild environmental insight with special reference to India. Sci Total Environ. 2020;728:138914.

4. Rammohan A, Rela M. COVID-19: could India still escape? J Glob Health. 2020; 10:1-4.

5. The Lancet. India Under COVID-19 Lockdown. Lancet. 2020;395:1315.

6. WHO. Coronavirus Disease Case Report 18 May 2020. World Health Organization 2020;2633

7. Sharma N, Hasan Z, Velayudhan A, A EM, Mangal DK, Gupta SD. Personal protective equipment: challenges and strategies to combat COVID- 19 in India: a narrative review. J Health Manag. (2020) 22:157-68.

8. Shenoi SB, Deshpande S, Jatti R. Impact of COVID-19 Lockdown on Patients
Undergoing Orthodontic Treatment: A Questionnaire Study. J Indian Orthod Soc. 2020;54(3):195-202.

9. Sayers MS, Newton JT. Patients' expectations of orthodontic treatment: Part 2-findings from a questionnaire survey. $\mathrm{J}$ Orthod. 2007;34(1):25-35.

10. Bartsch A, Witt E, Sahm G, Schneider S. Correlates of patient compliance with removable appliance wear. Am J Orthod Dentofac Orthop. 1993;104(4):378-86.

11. Lurie N, Carr BG. The Role of Telehealth in the Medical Response to Disasters. JAMA Internal Med. 2018;178(6):745-6.

12. Hollander JE, Carr BG. Virtually Perfect? Telemedicine for Covid-19. New Engl J Med. 2020;382(18):1679-81.

How to cite this article: Chatterjee O, Sharma K, Kumar $S$ et.al. Impact of the COVID-19 lockdown on Indian patients undergoing orthodontic treatment: a questionnaire based study. Int J Health Sci Res. 2022; 12(3):39-43. DOI: https://doi.org/10.52403/ijhsr.20220306 